University of Wollongong

Research Online

Faculty of Business - Papers (Archive)

Faculty of Business and Law

2018

Price discovery in short-term interest rate markets: Futures versus swaps

Alessandro Frino

University of Wollongong, afrino@uow.edu.au

Michael Garcia Santana

University of Wollongong, mgs012@uowmail.edu.au

Follow this and additional works at: https://ro.uow.edu.au/buspapers

Part of the Business Commons

Research Online is the open access institutional repository for the University of Wollongong. For further information contact the UOW Library: research-pubs@uow.edu.au 


\title{
Price discovery in short-term interest rate markets: Futures versus swaps
}

\author{
Abstract \\ This study examines price discovery at the short end of the yield curve by examining the lead-lag \\ relationship in the prices of Australian interest rate swap and bank accepted bill futures contracts. \\ Consistent with previous research, we find strong bidirectional flows of information between swap and \\ futures markets during daytime trading. However, the swap market leads price discovery during overnight \\ trading while futures markets lead swap markets on macroeconomic announcement days-both new \\ findings. We demonstrate and conclude that price discovery in derivatives at the short end of the yield \\ curve is driven by transaction costs. \\ Disciplines \\ Business \\ Publication Details \\ Frino, A. \& Garcia, M. (2018). Price discovery in short-term interest rate markets: Futures versus swaps. \\ Journal of Futures Markets, 38 (10), 1179-1188.
}




\title{
Price Discovery in Short-Term Interest Rate Markets: Futures versus Swaps
}

\author{
Alex Frino, Michael Garcia* \\ University of Wollongong, Wollongong, NSW, Australia
}

\begin{abstract}
This study examines price discovery at the short end of the yield curve by examining the lead-lag relationship in the prices of Australian interest rate swap and bank accepted bill futures contracts. Consistent with previous research, we find strong bi-directional flows of information between swap and futures markets during daytime trading. However, the swap market leads price discovery during overnight trading while futures markets lead swap markets on macroeconomic announcement days both new findings. We demonstrate and conclude that price discovery in derivatives at the short end of the yield curve is driven by transaction costs.
\end{abstract}

We would like to thank participants at the 2017 Sixth International Conference on Futures and Other Derivatives in Ningbo China and the research seminars at the University of Wollongong Business School for their helpful suggestions. Any errors or omissions are the responsibility of the authors alone.

*Corresponding author, University of Wollongong, Northfields Ave, Wollongong, NSW 2522, Australia. Tel: +61 (2) $4221 \quad$ 5190; $\quad$ Fax: +61 (2) $4221 \quad 4447 ; \quad$ Email: mgs012@uowmail.edu.au 


\section{INTRODUCTION}

This paper investigates price discovery in short-term interest rate markets. Specifically, we investigate the lead-lag relationship between price changes for two derivatives: interest rate swaps and interest rate futures. There is extensive literature examining the relationship between stock and stock index futures markets (e.g. Grunbichler, Longstaff and Schwartz, 1994; Min and Najand, 1999; Shyy, Vijayraghavan and Scott-Quinn, 1996) as well as stock and stock option markets (e.g. O’Connor, 1999; Stephan and Whaley, 1990; Chan, Chung and Johnson, 1993). There is also some research that examines the relationship between interest rate and interest rate futures markets (e.g. Scalia, 1998; Poskitt, 1999). However, limited research exists on price discovery across different types of interest rate derivatives markets. This is especially surprising since interest rate derivatives markets dwarf equity derivatives markets in terms of trading activity. ${ }^{1}$ To our knowledge, the only study that investigates price discovery across different interest rate derivatives markets is Poskitt (2007). In this study we bring further evidence to bear on this issue and provide some new insights.

Poskitt (2007) sets out to examine the possibility that "benchmark tipping” has occurred away from interest rate futures markets towards swap markets at the short end of the yield curve, as a consequence of the dramatic increase in swap volumes relative to the volumes of short-term interest rate futures in the UK. Examining data for the year to June 2003, Poskitt (2007) documents a largely contemporaneous relationship in price movements and concludes that information flows between futures and swaps and vice-versa for up to 20 minutes. However, he also finds that, over the very short term (one minute), information flows from futures to swaps are dominant. In this paper, we reexamine price discovery in swaps and short-term interest rate futures contracts and extend the findings in previous research in a number of ways. Firstly, we test the external validity of previous research by examining the Australian market in a more recent time period. ${ }^{2}$ Secondly, we extend previous research by examining price discovery on days of macroeconomic information 
announcements and in overnight markets - when private information, informed trading, and information asymmetries are likely to be high.

The literature develops at least two main theoretical explanations for the location of price discovery, which produce conflicting predictions in relation to short-term interest rate derivatives markets. Firstly, Grunbichler, Longstaff and Schwartz (1993) hypothesize and provide evidence that informed traders prefer to trade in markets that are opaque, since anonymity allows informed traders to trade without revealing their private information. This theory would imply that swap prices are likely to lead futures prices, as the over-the-counter (OTC) swap market has limited pre-and-post trade transparency and therefore will attract informed traders. Alternatively, Fleming, Ostdiek and Whaley (1996) recognize that price discovery occurs in markets where trading costs are lowest, as information-based trades are executed where they produce the highest profit. Therefore, given the relatively higher trading activity of short-term interest rate futures over swaps, futures markets are likely to be cheaper to trade than swaps (see Aitken et.al., 2004 - bid and ask spreads are related to trading volume in futures markets); and this theory predicts that futures markets will be the location of price discovery in interest rate futures markets. ${ }^{3}$ Hence, the theories for the location of price discovery produce conflicting predictions about whether the swap market is expected to lead the futures market at the short end of the yield curve. This is an empirical issue which we re-examine in this paper.

There is a considerable body of work examining the impact of the release of information on the relationship between stock index and stock index futures markets (see Chan, 1992; Frino, Walter and West, 2000). Such periods are particularly important, because they are characterized by an increase in private information, informed trading, and information asymmetry. These papers document a strengthening in the lead of the futures markets around macroeconomic releases, which is consistent with the predictions of the theory that low trading cost drives price discovery to futures markets during periods of high informed trading (Fleming, Ostdiek and Whaley, 1996). Macroeconomic 
information releases have an impact on prices of interest rate futures (see Ederington and Lee, 1993), and therefore are likely to create information asymmetries and informed trading around the time that they are released. This provides an ideal laboratory setting for further examining the location of price discovery in short-term interest rate markets during periods of high informed trading.

Poskitt (2007) notes that swaps trade 24 hours per day, while during the sample period he examines, UK interest rate futures traded during the day only (from 7:30 am to 6:00 pm). More recently, futures exchanges have moved to trading almost 24 hours per day. For example, the bank accepted bill futures contracts examined in this study currently trade around the clock, only breaking from trading between 4:30 and 5:08 pm and 7:00 am to 8:28 am. The more recent sample period we use, therefore, also enables us to extend previous research by examining price discovery in overnight short-term interest rate markets. The overnight market is particularly interesting in Australia, as it is punctuated by the opening of both US and UK markets, which creates price volatility (Frino and Hill, 2000; Zou, Rose and Pinfold, 2006). This is likely to create information asymmetry and informed trading, and therefore provides another natural laboratory experiment for testing the location of price discovery in the presence of higher informed trading.

The remainder of this paper is organized as follows. Section 2 describes the data and method; while Section 3 sets out the empirical results. Section 4 provides the conclusion and a number of suggestions for future research.

\section{DATA AND METHOD}

The data for this study are obtained from the Thomson Reuters Tick History Data Base (TRTH) maintained by the Securities Industries Research Centre of Asia-Pacific (SIRCA). From this dataset we extract 1-minute intraday bid and ask quote data for Australian 90-day bank accepted bill futures contracts traded on the Australian Security Exchange (ASX) from 1 January 2013 to 1 April 2016. The data includes the contract code, date and time of each quote, along with quoted price and volume for all futures contracts that are part of the quarterly expiration cycle (March, June, September and 
December). ${ }^{4}$ OTC quote data for the Australian 1-year interest rate swap contract is also collected from TRTH on a 1-minute intraday basis for the same sample period (1 January 2013 - 1 April 2016). This data set includes indicative bid and ask quotes supplied by approved dealers and contributors. ${ }^{5}$ Data for interest rate swap and futures contracts are collected for the period when both markets are open for trading, from 8:28 am to 4:30 pm (Daytime session) and 5:08 pm to 7:00 am (Overnight session). We calculate the mid-quote for both swap and futures as the average of the best bid and ask quotes at each 1-minute interval after removing weekends and holidays. Mid-quotes reduce the effect of bid-ask bounce, as explained in Hauptfleisch, Putnins and Lucey (2016).

Australian macroeconomic announcements are obtained from Bloomberg for the period 1 January 2013 - 1 April 2016. This data set includes the date, announcement content and time stamp for major macroeconomic announcements such as Average Weekly Wages, Current Account Balance, Building Approvals, Gross Domestic Product (GDP), Cash Target, and Unemployment. These announcement types significantly impact the interest rate market, as identified by Frino and Hill (2001) and Frino, Walter and West (2000).

\subsection{Transaction Costs in the Swap and Futures Markets}

Similarly to Fleming, Ostdiek and Whaley (1996), we begin by examining the liquidity and transaction costs of different securities, through comparing bid-ask quotes and daily turnover in the interest rate swap and futures markets. For both swaps and futures bid-ask spreads (BAS) are measured in basis points for each 1-minute interval using prevailing best bid and ask quotes, as in Zhou, Rose and Pinfold (2006). Daily volumes for swaps and futures are collected from AFMA (2017) as the daily average turnover in A $\$$ billion. ${ }^{6}$ Table I provides descriptive statistics for bid-ask spreads and average daily turnover for the daytime session (8:28 am to 4:30 pm), night-time session before midnight (5:08 $\mathrm{pm}$ to $11: 59 \mathrm{pm})$, and night-time session after midnight (12:00 am to 07:00 am). Table I documents that the bid-ask spread of swaps is many times greater than BAB futures 
across all periods examined - however these are not directly comparable. More importantly, the difference between bid-ask spreads of swaps and futures exhibits an intraday/intranight pattern. Table 1 and Figure 1 demonstrates that during the day, the difference in bid-ask spreads is greatest. However, in the first part of the evening trading session (before midnight) the bid-ask spreads begin to converge, while after midnight is when the difference in bid-ask spreads between swaps and BAB futures is smallest. In addition, Table I documents that the ratio of daily average futures turnover to daily average swap turnover is approximately 2.0 times (\$104.7 billion / \$53.4 billion) implying that the liquidity of BAB futures is much higher than swaps.

\section{$<$ INSERT TABLE I $>$}

The results in Table I suggest that price discovery between swaps and BAB futures can take on an intraday pattern. If price discovery is driven by transaction costs, then if swap prices are to lead futures market prices, this is most likely to happen during the overnight session - particularly after midnight when the cost of trading swaps approaches that of futures. In the remainder of this paper, we document the lead-lag relationship between price movements in swap and BAB futures prices during different times of the day and around information releases.

\section{$<$ INSERT FIGURE I $>$}

\section{2. $\quad$ Modeling Price Discovery}

Based on prior research, we implement a lead/lad model similar to Sims (1972) and Frino, Walter and West (2000) and Poskitt (2007), to investigate the price discovery relationship between the swap and futures markets during daytime and overnight trading. In addition, we examine the impact of macroeconomic information releases on information flow between these two markets. Coefficients of the lead/lag model are estimated by regressing various measures of 1-minute swap prices against lagged, contemporaneous and leading 1-minute futures prices as follows:

$$
\Delta S_{t}=\alpha+\sum_{k=-20}^{20} \beta_{t+k} \Delta F_{t+k}+u_{t}
$$


where $\Delta S_{t}$ is the change in the swap price over interval $t, \Delta F_{t}$ is the change in the futures price over interval $t$, and $u_{t}$ is the residual. ${ }^{7}$ Under Equation (1), the futures market leads the swap market when coefficients on lagged futures prices $(\mathrm{k}<0)$ are significant and coefficients on lead futures prices $(k>0)$ are insignificant. Alternatively, the swap market leads the futures market when coefficients on lagged futures prices $(\mathrm{k}<0)$ are insignificant and coefficients on lead futures prices $(\mathrm{k}>0)$ are significant. In addition, using a Wald test, Hypothesis 1 (H1) tests that the hypothesis that the sum of the first ten lead coefficients (i.e., $k=+1$ to $k=+10$ ) are equal to zero (H1: $\left.\sum_{k=1}^{10} \beta_{t+k}=0\right)$. Rejection of Hypothesis 1 indicates that information is transmitted from swap to futures markets. Similarly, Hypothesis 2 (H2) tests the hypothesis that the sum of the first ten lag coefficients (i.e., $\mathrm{k}=-1$ to $\mathrm{k}=-10$ ) are equal to zero $\left(\mathrm{H} 2: \sum_{k=-1}^{-10} \beta_{t+k}=0\right)$. The rejection of Hypothesis 2 implies that information is transmitted from the futures to the swaps. The simultaneous rejection of $\mathrm{H} 1$ and $\mathrm{H} 2$ indicates that price discovery occurs simultaneously in the interest rate swap and futures markets.

\section{RESULTS}

\subsection{Price Discovery Between Swaps and Futures During Daytime Trading}

Table II presents the results for the lead/lag model (Equation [1]) for daytime trading. ${ }^{8}$ Model 1 in Panel A demonstrates that, when the coefficients are estimated using the nearby futures contract for the independent variable, seven lagged futures prices $(k=-1$ to $k=-7)$ are significantly positive, which implies that the futures market leads the swap market by up to seven minutes. In addition, coefficients on six lead futures prices $(\mathrm{k}=+1$ to $\mathrm{k}=+6)$ are significantly positive at the 0.01 level, suggesting that information flows from the swap market to the futures market by up to six minutes. These results demonstrate that the transmission of information between the swap and futures markets is largely contemporaneous. When the deferred contract is used as independent variable (Model 2), two lead coefficients $(\mathrm{k}=+5$ and $\mathrm{k}=+6)$ become insignificant and one lag coefficient $(\mathrm{k}=-8)$ becomes 
significant, implying that lower transaction costs (see Table I) in the deferred contract increases the transmission of information from the futures market to the swap market to eight minutes in duration, and reduces the feedback from the swap market to the futures market to four minutes. Results using the deferred contract demonstrate that the price discovery relationship between the swap and futures markets is contemporaneous by up to four minutes; however, the futures market leads price discovery over the medium term. F-statistics reported in Panel B provide further evidence of the price discovery relationship between interest rate swap and futures. The rejection of hypotheses 1 and 2 demonstrates a strong bi-directional flow of information between the swap and futures markets. Results in Table II confirm previous findings that price discovery between the short-term interest rate swap and futures markets is largely contemporaneous.

\section{$<$ INSERT TABLE II $>$}

\subsection{The Impact of Macroeconomic Information Releases}

Panel A of Table III documents that, when the lead-lag model is estimated on non-announcement days, seven lagged futures prices ( $\mathrm{k}=-1$ to $\mathrm{k}=-7)$ are significantly positive, which implies that the futures market leads the swap market by up to seven minutes. ${ }^{9}$ In addition, coefficients on seven lead futures prices $(\mathrm{k}=+1$ to $\mathrm{k}=+7)$ are significantly positive at the 0.01 level, suggesting a seven minutes feedback from the swap market to the futures market. These results demonstrate that the price discovery relationship between the swap and futures markets is highly contemporaneous on non-announcement days. When the lead-lag model is estimated on macroeconomic announcement days, four lead futures prices $(k=+4$ to $k=+7)$ become insignificant, implying that the futures market becomes the source of price discovery in the short-term interest rate market on announcement days. The lead of the futures market is also evidence in the magnitude of the significant lead and lag coefficients on announcement days. The sum of the significant lag coefficients ( $k=-1$ to $k=-7)$ is 0.276, three times the size of the significant lead coefficients $(k=+1$ to $k=+3)$ of 0.090 . These findings indicate that the futures market leads price discovery on days with macroeconomic 
information which are accompanied by increases in informed trading and information asymmetry in the market. This result is consistent with the Fleming, Ostdiek and Whaley (1996) theory that price discovery occurs in the market with lowest transaction costs. As demonstrated in Table I, the cost of trading in the futures market is relatively lower than the cost of trading in the interest rate swap market during the daytime session.

\section{$<$ INSERT TABLE III $>$}

\subsection{Price Discovery in Overnight Trading Markets}

Table IV presents the results for the lead/lag model in overnight markets. Panel A documents that, when the coefficients are estimated for the overnight session before midnight, two lagged futures prices $(\mathrm{k}=-1$ and $\mathrm{k}=-2)$ around the contemporaneous coefficient $(\mathrm{k}=0)$ are significantly positive at the 0.01 level, which implies that the futures market leads the swap market by up to two minutes. In addition, coefficients on two lead futures prices $(\mathrm{k}=+1$ and $\mathrm{k}=+2)$ around the contemporaneous coefficient $(\mathrm{k}=0)$ are significantly positive at the 0.01 level, suggesting that information flows from the swap market to the futures market by up to two minutes. These results demonstrate that the transmission of information between the swap and futures markets is largely contemporaneous during overnight trading before midnight. When coefficients are estimated for the overnight session after midnight, the lag coefficient $\mathrm{k}=-2$ becomes insignificant, implying that higher transaction costs (see Table I) in the futures market after midnight reduce information transmission from the futures market to the swap market from two minutes to one minute in duration. These results demonstrate a largely contemporaneous relationship between the swap and futures market in the overnight market before midnight; however, the swap market becomes the source of price discovery in the second half of the overnight session. F-statistics reported in Panel B provide an additional insight into the price discovery relationship between interest rate swap and futures in overnight markets. The rejection of hypotheses 1 and 2 in the session before midnight demonstrates a strong bi-directional flow of information between the swap and futures markets. However, the rejection of hypothesis 1 and 
failure to reject hypothesis 2 in the session after midnight confirms that the swap market leads the futures market during this time period. These findings indicate that the swap market leads price discovery around the time that the US and UK markets opens for trading - a period which previous research demonstrates increases information asymmetry and price volatility in the Australian overnight market.

\section{$<$ INSERT TABLE IV $>$}

\section{CONCLUSION}

This paper examines the price discovery relationship that exists between the interest rate swap and futures markets. In this study, we provide evidence of a strong bi-directional flow of information between the swap and futures markets during daytime trading sessions. However, the lead/lag relationship between interest rate swap and futures contracts is influenced by macroeconomic information releases and overnight trading sessions - periods characterised by elevations in private information and informed trading. Specifically, we find that futures market prices lead the transmission of information during macroeconomic information releases when transaction costs are relatively lower in the futures market relative to the swap market. On the contrary, swap market prices lead price discovery during overnight trading after midnight, which are likely to be driven by

an increase in transactions costs for futures markets. These results are consistent with the theory that price discovery is driven by transaction costs and liquidity. 


\section{APPENDIX}

\section{A.I: SWAP MARKET BACKGROUND}

Swaps were first traded in the 1980s among companies looking to avoid capital controls from the British government. Since then, the swap market has grown rapidly and expanded into various types and countries. As of 2016, swaps have become one of the most important financial instruments in Australia, with an approximate average daily turnover of $\mathrm{A} \$ 58.5$ billion and an average transaction size that ranges between $\mathrm{A} \$ 47$ and $\mathrm{A} \$ 100$ million (see AFMA, 2017). This level of liquidity represents a 30\% increase from 2010 according to AFMA (2017). The popularity of interest rate swaps reflects how simple swaps can be executed by companies and financial institutions to hedge against interest rate risk (Bicksler and Chen, 1986). Nevertheless, the rise of interest rate swaps has increased the risk of manipulation by some market participants. For example, British and US regulators fined Barclays and Deutsche Bank in 2012 and 2015, respectively, over charges of manipulating the London Inter-Bank Offered Rate (LIBOR) which is used as a benchmark to settle interest rate swaps in the UK (Perkins and Mortby, 2015). As a response to prevent manipulation in the swap market, regulators around the world introduced new regulations such as the creation of an alternative risk-free benchmark and disclosure of live and executable prices by prime banks (Duffie and Stein, 2015).

\section{A.II: INSTITUTIONAL DETAIL}

In Australia, the 90-day bank accepted bill futures contract was launched in 1979. Since then, the 90-day BABs futures contract has become one of the ten most liquid contracts in the world, with an average daily turnover of 83,000 contracts in 2012, seven times higher than the turnover of the spot market (data in a private communication from the ASX). The 90-day BABs trade at the ASX Trade24 for four expiry months (March, June, September and December) from 8:28 am AEST to 4:30 pm AEST and 5:08 pm AEST to 7:00 am AEST during the winter period, as well as from 8:28 am AEST to 4:30 pm AEST and 5:08 pm AEST to 7:30 am AEST during the summer period. The 
winter period is from the second Sunday in March until the first Sunday in November; in addition, the summer period is from the first Sunday in November until the second Sunday in March.

Australian interest rate swaps are mainly traded in the OTC market. OTC swap trading includes traditional voice dealers and exchange-like trading platforms with central limit order books. In Australia, around $60 \%$ of swaps trading is dominated by voice dealers, and only a small fraction of trades is executed on electronic trading platforms such as the Australian Market Licence (AML) regime, swap execution facilities (SEF) and multilateral trading facilities (MTF). A voice trading venue refers to an interdealer market where clients negotiate prices with dealers directly over the phone. Voice trading is usually supported by electronic displays, email or text messages. As an alternative to voice venues, electronic trading provides higher levels of pre-and-post trade transparency in the OTC market. Electronic trading covers four main trading mechanisms. 1. Request-for-quote (RFQ) trading allows market participants to select the best quoted price from an auction with multiple dealers. In the RFQ process, a client submits an intention to buy or sell a security, and approved dealers respond with their best bid and ask quotes. The dealer with the best quoted price wins the auction and trades with the client. 2. Central limit order books trading is an exchange-like venue where market participants continuously trade on quotes following some priority rules. 3. Fixing and matching sessions are where approved dealers submit indicative bid-ask quotes used to calculate an average fixed price during the fixing session. Then, market participants submit firm quotes to trade at the fixed price during the matching session. 4. Click-to-trade trading provides market participants with an electronic trading venue where prices are displayed in real time and participants can choose the price and dealer to execute the trade. As of 2012, central clearing was not widely introduced in the Australian interest rate derivative market. Instead, many of the banks dealing in the OTC market offer clients their own clearing services. 


\section{REFERENCES}

AFMA [Australian Financial Markets Association] (2017). 2017 Australian Financial Markets Report. AFMA.

Aitken, M.J., Frino, A., Hill, A.M., \& Jarnecic, E. (2004), The impact of electronic trading on bidask spreads: Evidence from futures markets in Hong Kong, London, and Sydney, Journal of Futures Markets, 24, 675-96.

ASX [Australian Security Exchange] (2014). 90 Day Bank Accepted Bill Futures and Options Interest Rate Markets Fact Sheet. ASX

ASX [Australian Security Exchange] (2018). Interest Rate Derivatives Price and Valuation Guide. ASX.

Bicksler, J., \& Chen, A.H. (1986), An economic analysis of interest rate swaps, The Journal of Finance, 41, 645-55.

Chan, K. (1992), A further analysis of the lead-lag relationship between the cash market and stock index futures market, The Review of Financial Studies, 5, 132-52.

Chan, K., Chung, Y.P., \& Johnson, H. (1993), Why option prices lag stock prices: A trading-based explanation, Journal of Finance, 48, 1957-67.

Duffie, D., \& Stein, J.C. (2015), Reforming LIBOR and other financial market benchmarks, Journal of Economic Perspectives, 29, 191-212.

Ederington, L.H., \& Lee, J.H. (1993), How markets process information: News releases and volatility, Journal of Finance, 48, 1161-91.

Fleming, J., Ostdiek, B., \& Whaley, R.E. (1996), Trading costs and the relative rates of price discovery in stock, futures, and option markets, The Journal of Futures Markets, 16, 353-87.

Frino, A., \& Hill, A. (2000), Intranight trading behaviour, Working paper, The University of Sydney. 
Frino, A., \& Hill, A. (2001), Intraday futures market behaviour around major scheduled macroeconomic announcements: Australian evidence, Journal of Banking and Finance, 25, 1319-37.

Frino, A., Walter, T., \& West, A. (2000), The lead-lag relationship between equities and stock index futures markets around information releases, Journal of Futures Markets, 20, 467-87.

Goodhart, C.A.E., \& Figliuoli, L. (1991), Every minute counts in financial markets, Journal of International Money and Finance, 10, 23-52.

Grünbichler, A., Longstaff, F.A., \& Schwartz, E.S. (1994), Electronic screen trading and the transmission of information: An empirical examination, Journal of Financial Intermediation, 3, 166-87.

Hauptfleisch, M., Putni, T.l.J., \& Lucey, B. (2016), Who sets the price of gold? London or New York, Journal of Futures Markets, 36, 564-86.

Min, J.H. (1999), A further investigation of the lead-lag relationship between the spot market and stock index futures: Early evidence from Korea, The Journal of Futures Markets, 19, 217-32.

Perkins, J., \& Mortby, P. (2015), Evolving financial benchmarks: The impact on legacy contracts, Journal of Securities Operations \& Custody, 7, 296-304.

Poskitt, R. (1999), Price discovery in cash and futures interest rate markets in New Zealand, Applied Financial Economics, 9, 355-64.

Poskitt, R. (2007), Benchmark tipping and the role of the swap market in price discovery, The Journal of Futures Markets, 27, 981-1001.

O'Connor, M.L. (1999), The cross-sectional relationship between trading costs and lead/lag effects in stock \& option markets, Financial Review, 34, 95-117

RBA [Reserve Bank of Australia] (2015). Report on the Australian OTC derivatives market. RBA Scalia, A. (1998), Information transmission and causality in the Italian Treasury bond market, Journal of Empirical Finance, 5, 361-84. 
Shyy, G., Vijayraghavan, V., \& Scott-Quinn, B. (1996), A further investigation of the lead-lag relationship between the cash market and stock index futures market with the use of bid/ask quotes: The case of France, Journal of Futures Markets, 16, 405.

Sims, C.A. (1972), Money, income, and causality, The American Economic Review, 62, 540-52.

Stephan, J.A., \& Whaley, R.E. (1990), Intraday price change and trading volume relations in the stock and stock option markets, Journal of Finance, 45, 191-220.

Zou, L., Rose, L.C., \& Pinfold, J.F. (2006), Intra-night trading behaviour of Australian treasury-bond futures overnight options, International Review of Financial Analysis, 15, 415-33. 


\section{FIGURE I}

Intraday Bid-Ask Spreads in the Short-Term Interest Rate Market

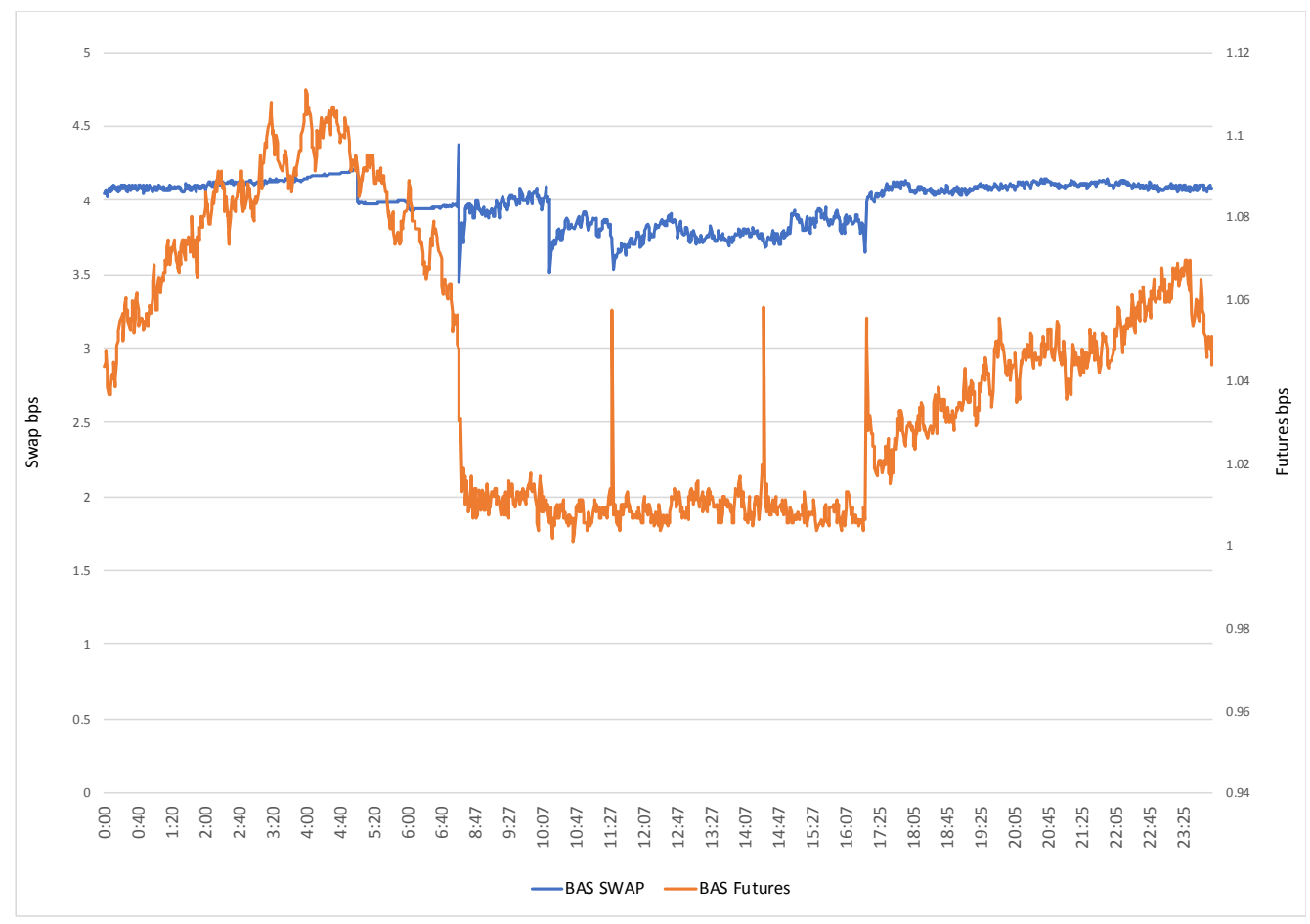

Note. Table I reports intraday bid-ask spreads (BAS) in basis points for interest rate swaps and futures between 1 January 2013 and 1 April 2016. Bid-ask spreads for the futures market are calculated in basis points for each 1-minute interval by subtracting the prevailing bid quote from the prevailing ask quote. Bid-ask spreads for the swap market are similarly calculated using indicative bid and ask quotes provided by approved contributors. Bid-ask spreads in Table I are calculated for three trading sessions - daytime session from 8:28 am to 4:30 pm, night-time session before midnight from 5:08 pm to 11:59 pm, and night-time session after midnight from 12:00 am to 7:00 am. 
TABLE I

Bid-Ask Spreads and Trading Volumes in the Short-Term Interest Rate Market

\begin{tabular}{|c|c|c|c|c|c|c|c|c|c|}
\hline & \multicolumn{7}{|c|}{ Bid-Ask Spreads (in basis points) } & & \\
\hline & \multicolumn{3}{|c|}{ Daytime Session } & \multicolumn{2}{|c|}{$\begin{array}{l}\text { Night Time } \\
\text { Before } \\
\text { Midnight }\end{array}$} & \multicolumn{2}{|c|}{$\begin{array}{l}\text { Night Time } \\
\text { After } \\
\text { Midnight }\end{array}$} & \multicolumn{2}{|c|}{$\begin{array}{c}\text { Daily Avg. } \\
\text { Turnover } \\
\text { (A\$ B) }\end{array}$} \\
\hline & Swap & Futures & Deferred & Swap & Futures & Swap & Futures & Swap & Futures \\
\hline Mean & 3.877 & 1.006 & 1.005 & 3.970 & 1.025 & 3.853 & 1.038 & 53.4 & 104.7 \\
\hline SD. & 1.783 & 0.013 & 0.010 & 1.799 & 0.066 & 1.769 & 0.119 & 7.2 & 6.1 \\
\hline Maximum & 7.983 & 1.120 & 1.079 & 7.985 & 1.886 & 7.988 & 2.0 & 58.5 & 109.5 \\
\hline Minimum & 1.406 & 1.0 & 1.0 & 1.0 & 1.0 & 1.0 & 1.0 & 48.4 & 95.8 \\
\hline
\end{tabular}

Note. Table I reports descriptive statistics for bid-ask spreads (BAS) and daily average turnover for interest rate swaps and futures between 1 January 2013 and 1 April 2016. Bid-ask spreads for the futures market are calculated in basis points for each 1-minute interval by subtracting the prevailing bid quote from the prevailing ask quote. Bid-ask spreads for the swap market are similarly calculated using indicative bid and ask quotes provided by approved contributors. Bid-ask spreads in Table I are calculated for three trading sessions daytime session from 8:28 am to 4:30 pm, night-time session before midnight from 5:08 pm to 11:59 pm, and night-time session after midnight from 12:00 am to 7:00 am. We estimate swap and BAB futures daily average turnover figures in Australian dollars for a sample period approximating the sample period examined in this paper using AFMA survey data for 2017 and after adjusting for exchange rates sourced from the RBA. 
TABLE II

The Lead/Lag Relationship Between Swap and Futures Prices in Daytime Trading

\begin{tabular}{lccccc}
\hline \multicolumn{2}{l}{ Coefficients from lead/lag OLS regression } & & & \\
& \multicolumn{2}{c}{ Nearby Contract } & & \multicolumn{2}{c}{ Deferred Contract } \\
\cline { 2 - 3 } \cline { 5 - 6 } & Coefficient & T-statistic & & Coefficient & T-statistic \\
\hline Intercept & 0.0000 & 0.36 & & 0.0000 & 0.18 \\
$\boldsymbol{\beta} \mathrm{t}+10$ & 0.0014 & 0.42 & & 0.0042 & 1.03 \\
$\boldsymbol{\beta} \mathrm{t}+9$ & 0.0018 & 0.50 & & 0.0051 & 1.70 \\
$\boldsymbol{\beta} \mathrm{t}+8$ & 0.0055 & 1.50 & & 0.0013 & 0.23 \\
$\boldsymbol{\beta} \mathrm{t}+7$ & 0.0069 & 1.87 & & 0.0020 & 0.67 \\
$\boldsymbol{\beta} \mathrm{t}+6$ & 0.0164 & $4.43^{* * *}$ & & 0.0032 & 1.05 \\
$\boldsymbol{\beta} \mathrm{t}+5$ & 0.0138 & $3.74^{* * *}$ & & 0.0057 & 1.88 \\
$\boldsymbol{\beta} \mathrm{t}+4$ & 0.0136 & $3.69^{* * *}$ & & 0.0129 & $4.25 * * *$ \\
$\boldsymbol{\beta} \mathrm{t}+3$ & 0.0205 & $5.55^{* * *}$ & & 0.0164 & $5.43^{* * *}$ \\
$\boldsymbol{\beta} \mathrm{t}+2$ & 0.0249 & $6.74^{* * *}$ & & 0.0261 & $8.64 * * *$ \\
$\boldsymbol{\beta} \mathrm{t}+1$ & 0.0389 & $10.57^{* * *}$ & & 0.0397 & $13.13^{* * *}$ \\
$\boldsymbol{\beta} \mathrm{t}$ & 0.3077 & $83.64^{* * *}$ & & 0.3304 & $109.49^{* * *}$ \\
$\boldsymbol{\beta} \mathrm{t}-1$ & 0.0495 & $13.46^{* * *}$ & & 0.0380 & $12.60^{* * *}$ \\
$\boldsymbol{\beta} \mathrm{t}-2$ & 0.0228 & $6.19^{* * *}$ & & 0.0289 & $9.56^{* * *}$ \\
$\boldsymbol{\beta} \mathrm{t}-3$ & 0.0160 & $4.34^{* * *}$ & & 0.0173 & $5.73^{* * *}$ \\
$\boldsymbol{\beta} \mathrm{t}-4$ & 0.0275 & $7.49^{* * *}$ & & 0.0159 & $5.26^{* * *}$ \\
$\boldsymbol{\beta} \mathrm{t}-5$ & 0.0074 & $2.02^{* *}$ & 0.0011 & 0.37 \\
$\boldsymbol{\beta} \mathrm{t}-6$ & 0.0132 & $3.60^{* * *}$ & 0.0103 & $3.42^{* * *}$ \\
$\boldsymbol{\beta} \mathrm{t}-7$ & 0.0266 & $7.26^{* * *}$ & 0.0159 & $5.28^{* * *}$ \\
$\boldsymbol{\beta} \mathrm{t}-8$ & 0.0052 & 1.42 & & 0.0123 & $4.09 * * *$ \\
$\boldsymbol{\beta} \mathrm{t}-9$ & 0.0022 & 0.60 & & 0.0060 & 1.99 \\
$\boldsymbol{\beta} \mathrm{t}-10$ & 0.0064 & 1.76 & & 0.0019 & 0.62 \\
& & & &
\end{tabular}

Panel B: Hypothesis tests (F-test)

\begin{tabular}{lll}
$\mathrm{H} 1: \sum_{k=1}^{10} \beta_{t+k}$ & $100.23^{* * *}$ & $107.64^{* * *}$ \\
$\mathrm{H} 2: \sum_{k=-1}^{-10} \beta_{t+k}$ & $107.92^{* * *}$ & $139.78^{* * *}$ \\
\hline
\end{tabular}

Note. Table II reports regression coefficients for the lead/lag model for daytime trading (8:28 am to 4:30 pm) for the period 1 January 2013 to 1 April 2016. Model 1 presents the coefficients estimated using an OLS regression with 1-minute intraday observations where the dependent variable is the change in the swap price and the independent variable is the change in the nearest-to-delivery quarterly futures contract price. Model 2 presents the coefficients estimated when the independent variable is the change in the quarterly deferred futures contract price. Panel B reports the F-statistics of Wald tests on coefficient restrictions for the two hypotheses. ${ }^{* *} \mathrm{p}<0.05,{ }^{* * *} \mathrm{p}<0.01$. 
TABLE III

The Lead/Lag Relationship Between Swap and Futures Prices on Announcement and Non-Announcement Days

\begin{tabular}{lccccc}
\hline \multicolumn{2}{l}{ Coefficients from lead/lag OLS regression } & & & \\
& \multicolumn{2}{c}{ Announcement Days } & & Non-Announcement Days \\
\cline { 2 - 3 } \cline { 5 - 6 } & Coefficient & T-statistic & & Coefficient & T-statistic \\
\cline { 2 - 3 } Intercept & 0.0000 & 0.06 & & 0.0000 & 0.43 \\
$\boldsymbol{\beta} \mathrm{t}+10$ & 0.0089 & 1.19 & & 0.0017 & 0.30 \\
$\boldsymbol{\beta} \mathrm{t}+9$ & 0.0026 & 0.35 & & 0.0008 & 0.19 \\
$\boldsymbol{\beta} \mathrm{t}+8$ & 0.0065 & 0.87 & & 0.0050 & 1.16 \\
$\boldsymbol{\beta} \mathrm{t}+7$ & -0.0032 & -0.44 & & 0.0100 & $2.30^{* *}$ \\
$\boldsymbol{\beta} \mathrm{t}+6$ & 0.0019 & 0.25 & & 0.0147 & $3.40^{* * *}$ \\
$\boldsymbol{\beta} \mathrm{t}+5$ & 0.0112 & 1.51 & & 0.0137 & $3.18^{* * *}$ \\
$\boldsymbol{\beta} \mathrm{t}+4$ & 0.0079 & 1.07 & & 0.0152 & $3.52^{* * *}$ \\
$\boldsymbol{\beta} \mathrm{t}+3$ & 0.0282 & $3.79^{* * *}$ & & 0.0160 & $3.71^{* * *}$ \\
$\boldsymbol{\beta} \mathrm{t}+2$ & 0.0333 & $4.48^{* * *}$ & & 0.0194 & $4.50^{* * *}$ \\
$\boldsymbol{\beta} \mathrm{t}+1$ & 0.0292 & $3.93^{* * *}$ & & 0.0432 & $10.03^{* * *}$ \\
$\boldsymbol{\beta} \mathrm{t}$ & 0.3992 & $53.81^{* * *}$ & & 0.2689 & $62.44^{* * *}$ \\
$\boldsymbol{\beta} \mathrm{t}-1$ & 0.0747 & $10.06^{* * *}$ & & 0.0401 & $9.31^{* * *}$ \\
$\boldsymbol{\beta} \mathrm{t}-2$ & 0.0333 & $4.48^{* * *}$ & & 0.0169 & $3.93^{* * *}$ \\
$\boldsymbol{\beta} \mathrm{t}-3$ & 0.0276 & $3.31^{* * *}$ & & 0.0115 & $2.68^{* * *}$ \\
$\boldsymbol{\beta} \mathrm{t}-4$ & 0.0525 & $7.09^{* * *}$ & & 0.0157 & $3.64^{* * *}$ \\
$\boldsymbol{\beta} \mathrm{t}-5$ & 0.0306 & $4.13^{* * *}$ & 0.0015 & 0.34 \\
$\boldsymbol{\beta} \mathrm{t}-6$ & 0.0189 & $2.55^{* *}$ & 0.0097 & $2.26^{* * *}$ \\
$\boldsymbol{\beta} \mathrm{t}-7$ & 0.0391 & $5.28^{* * *}$ & 0.0205 & $4.79^{* * *}$ \\
$\boldsymbol{\beta} \mathrm{t}-8$ & 0.0030 & 0.41 & & 0.0056 & 1.31 \\
$\boldsymbol{\beta} \mathrm{t}-9$ & -0.0033 & -0.45 & & 0.0031 & 0.72 \\
$\boldsymbol{\beta} \mathrm{t}-10$ & -0.0025 & -0.34 & & 0.0027 & 0.28
\end{tabular}

Panel B: Hypothesis tests (F-test)

\begin{tabular}{lll}
$\mathrm{H} 1: \sum_{k=1}^{10} \beta_{t+k}$ & $22.67^{* * *}$ & $68.25^{* * *}$ \\
$\mathrm{H} 2: \sum_{k=-1}^{-10} \beta_{t+k}$ & $48.71^{* * *}$ & $51.84^{* * *}$ \\
\hline
\end{tabular}

Note. Table III reports the regression coefficients for the lead/lag model on macro-economic announcement and non-announcement days for the period 1 January 2013 to 1 April 2016. Panel A presents the coefficients estimated using an OLS regression with 1-minute intraday observations where the dependent and independent variables are the change in the swap price and nearby futures contract price, respectively. Panel B reports the F-statistic for Wald tests on coefficient restrictions for the two hypotheses. ${ }^{* *} \mathrm{p}<0.05$, *** $\mathrm{p}<0.01$. 
TABLE IV

The Lead/Lag Relationship Between Swap and Futures Prices in Overnight Markets

\begin{tabular}{|c|c|c|c|c|}
\hline & \multicolumn{2}{|c|}{ Before Midnight } & \multicolumn{2}{|c|}{ After Midnight } \\
\hline & Coefficient & T-statistic & Coefficient & T-statistic \\
\hline Intercept & 0.0000 & 0.02 & 0.0000 & 0.04 \\
\hline $\boldsymbol{\beta} \mathrm{t}+10$ & 0.0044 & 1.15 & -0.0042 & -0.29 \\
\hline $\boldsymbol{\beta} \mathrm{t}+9$ & 0.0132 & $3.46^{* * *}$ & 0.0155 & $3.87^{* * *}$ \\
\hline $\boldsymbol{\beta} \mathrm{t}+8$ & -0.0005 & -0.12 & -0.0007 & -0.17 \\
\hline $\boldsymbol{\beta} \mathrm{t}+7$ & 0.0025 & 0.65 & 0.0097 & $2.43 * *$ \\
\hline $\boldsymbol{\beta} \mathrm{t}+6$ & 0.0111 & $2.92 * * *$ & 0.0166 & $4.15^{* * *}$ \\
\hline $\boldsymbol{\beta} \mathrm{t}+5$ & 0.0023 & 0.61 & 0.0036 & 0.91 \\
\hline $\boldsymbol{\beta} \mathrm{t}+4$ & 0.0084 & $2.21 * *$ & 0.0025 & 0.61 \\
\hline $\boldsymbol{\beta} \mathrm{t}+3$ & 0.0042 & 1.11 & -0.0010 & -0.57 \\
\hline $\boldsymbol{\beta} \mathrm{t}+2$ & 0.0255 & $6.75^{* * *}$ & 0.0335 & $8.41 * * *$ \\
\hline $\boldsymbol{\beta} \mathrm{t}+1$ & 0.0300 & $7.96 * * *$ & 0.0168 & $4.21 * * *$ \\
\hline $\boldsymbol{\beta} \mathrm{t}$ & 0.0247 & $6.55^{* * *}$ & 0.1898 & $47.73^{* * *}$ \\
\hline $\boldsymbol{\beta} \mathrm{t}-1$ & 0.2355 & $62.52 * * *$ & 0.0181 & $4.56^{* * *}$ \\
\hline $\boldsymbol{\beta} \mathrm{t}-2$ & 0.0158 & $4.21^{* * *}$ & 0.0014 & 0.34 \\
\hline $\boldsymbol{\beta} \mathrm{t}-3$ & 0.0050 & 1.32 & 0.0068 & 1.73 \\
\hline $\boldsymbol{\beta} \mathrm{t}-4$ & 0.0055 & 1.46 & 0.0067 & 1.68 \\
\hline $\boldsymbol{\beta} \mathrm{t}-5$ & 0.0067 & 1.80 & -0.0052 & -1.31 \\
\hline $\boldsymbol{\beta} \mathrm{t}-6$ & 0.0097 & $2.59 * * *$ & 0.0073 & 1.85 \\
\hline $\boldsymbol{\beta}$ t-7 & 0.0039 & 1.05 & -0.0047 & -0.47 \\
\hline $\boldsymbol{\beta}$ t-8 & -0.0048 & -1.29 & 0.0027 & 0.69 \\
\hline $\boldsymbol{\beta}$ t -9 & 0.0065 & 1.74 & -0.0079 & -2.00 \\
\hline $\boldsymbol{\beta} \mathrm{t}-10$ & 0.0037 & 0.99 & 0.0018 & 0.67 \\
\hline \multicolumn{5}{|c|}{ Panel B: Hypothesis tests (F-test) } \\
\hline $\mathrm{H} 1: \sum_{k=1}^{10} \beta_{t+k}$ & & $43.22 * * *$ & & $14.22 * * *$ \\
\hline $\mathrm{H} 2: \sum_{k=-1}^{-10} \beta_{t+k}$ & & $25.33^{* * *}$ & & 1.93 \\
\hline
\end{tabular}

Note. Table II reports the regression coefficients of the lead/lag model on overnight trading before midnight (5:08 pm to $11: 59 \mathrm{pm})$ and after midnight $(12: 00 \mathrm{am}$ to $7: 00 \mathrm{am})$ for the period 1 January 2013 to 1 April 2016. Panel A presents the coefficients estimated using an OLS regression with 1-minute intraday observations where the dependent and independent variables are the change in the swap price and nearby futures contract price, respectively. Panel B reports the F-statistics of Wald tests on coefficient restrictions for the two hypotheses. $* * \mathrm{p}<0.05, * * * \mathrm{p}<0.01$. 


\section{Footnotes}

${ }^{1}$ Similarly to the UK, trading in interest rate swaps in Australia dwarfs trading in equity futures. For example, the ratio of average daily swap volume to futures volume in Australia for 2016 is approximately 9.8 times (\$58.5 billion / \$ 6.0 billion) [data sourced from AFMA 2017].

${ }^{2}$ The relative size of swap turnover to short term interest rate futures market turnover for the Australian sample we examine in this study is similar to that examined by Poskitt (2007). For example, in his sample, the ratio of average daily futures volume to swap volume in April 2004 is approximately 2.7 times (£68 billion /£25 billion) [see page 984], the analogous ratio for the sample that we examine in this study is approximately 2 times ( $\$ 104.7$ billion $/ \$ 53.4$ billion) [see Table I].

${ }^{3}$ Poskitt (2007) explains that benchmark tipping occurs when market participants find it advantageous to use another instrument for pricing and hedging purposes and this shift is “self-reinforcing” [p. 982].

${ }^{4}$ The 90-day Bank Accepted Bill futures contract is quoted as the yield deducted from an index of 100 (ASX, 2014).

${ }^{5}$ Indicative quotes in the OTC swap market are expressed in yields. We convert the quotes to prices by deducting the yield from 100. Although actual quotes are not available for the swap market, indicative mid-quotes are used as a proxy for actual mid-quote prices. Goodhart and Figliuoli (1991) explain that dealers avoid giving misleading quotes in the OTC market to prevent damaging their reputation. Poskitt (2007) also uses indicative quotes in his research.

${ }^{6}$ Since transaction prices and volumes are not available for the OTC swap market, we estimate swap and BAB futures daily average turnover figures in Australian dollars for a sample period approximating the sample period examined in this paper based on the AFMA survey data for 2017 and after adjusting for exchange rates sourced from the RBA.

${ }^{7}$ We ignore the 20 minutes before and after trading breaks and avoid comparing prices across market breaks as in Frino, Walter and West (2000).

${ }^{8}$ For simplicity, we report the first ten leads and lags coefficients, however, the lead/lag model is estimated using twenty leads and lags as explained in Equation (1).

${ }^{9}$ Table III presents the coefficients estimated using the nearby futures contract as the independent variable. In addition, we estimate the lead/lag model on announcement and non-announcement days using the deferred futures contract and find similar results under the two models. 